\title{
The dose effect of ephedrine on the onset time and intubating conditions after cisatracurium administration
}

\author{
Dong Guk Cha, Kyo Sang Kim, Ji Seon Jeong, and Hye Mee Kwon \\ Department of Anesthesiology and Pain Medicine, Hanyang University College of Medicine, Seoul, Korea
}

Background: The aim of this randomized, double-blind, placebo-controlled study was to evaluate dose effects of ephedrine pretreatment on the onset time and intubating conditions after cisatracurium administration.

Methods: A total of 140 adult patients were randomized into 4 groups to receive either $30 \mu \mathrm{g} / \mathrm{kg}$ ephedrine (Group 30, n = 35), $70 \mu \mathrm{g} / \mathrm{kg}$ ephedrine (Group 70, $\mathrm{n}=35$ ), $110 \mu \mathrm{g} / \mathrm{kg}$ ephedrine (Group 110, $\mathrm{n}=35$ ), $3 \mathrm{ml}$ normal saline (Group C, $\mathrm{n}$ = 35) as pretreatment given $30 \mathrm{~s}$ before anesthetic induction. Neuromuscular block was achieved with $0.15 \mathrm{mg} / \mathrm{kg}$ cisatracurium, evaluated accelomyographically with train-of-four stimulation. An anesthesiologist blinded to patient grouping assessed the intubating conditions $1.5 \mathrm{~min}$ after cisatracurium administration.

Results: An onset time of $70 \mathrm{~s}$ was obtained in the ephedrine groups (Group 30: $155.4 \pm 44.7 \mathrm{~s}$, Group 70: $152.6 \pm 40.3 \mathrm{~s}$, Group 110: $151.2 \pm 51.6$ s) compared to Group C (224.6 \pm 56.9 s) after $0.15 \mathrm{mg} / \mathrm{kg}$ of cisatracurium $(\mathrm{P}<0.001)$. Ephedrine doses of either 70 or $110 \mu \mathrm{g} / \mathrm{kg}$ for pretreatment significantly improved intubating conditions $(\mathrm{P}<0.05)$. Systolic and diastolic blood pressure and heart rate at $1 \mathrm{~min}$ after tracheal intubation were significantly increased than other times in all groups $(\mathrm{P}<0.001)$, with no differences among the groups. However, 5 patients in Group 110 experienced marked hypertension (systolic/diastolic blood pressure: > 200/100 $\mathrm{mmHg}$ ) $1 \mathrm{~min}$ after tracheal intubation with no patients in other groups.

Conclusions: We conclude that pre-treatment with ephedrine $70 \mu \mathrm{g} / \mathrm{kg}$ improved intubating conditions $1.5 \mathrm{~min}$ after cisatracurium administration and facilitated the onset of neuromuscular block (70 s) without adverse hemodynamic effects. (Korean J Anesthesiol 2014; 67: 26-31)

Key Words: Cisatracurium, Ephedrine, Hemodynamics, Intubation.

\footnotetext{
Received: November 18, 2013. Revised: December 11, 2013. Accepted: December 20, 2013.

Corresponding author: Kyo Sang Kim, M.D., Ph.D., Department of Anesthesiology and Pain Medicine, Hanyang University College of Medicine, 222, Wangsimni-ro, Seongdong-gu, Seoul 133-792, Korea. Tel: 82-2-2290-8680, Fax: 82-2-2299-0742, E-mail: kimks@hanyang.ac.kr

(c) This is an open-access article distributed under the terms of the Creative Commons Attribution Non-Commercial License (http:// creativecommons.org/licenses/by-nc/3.0/), which permits unrestricted non-commercial use, distribution, and reproduction in any medium, provided the original work is properly cited.
} 


\section{Introduction}

Cisatracurium, a benzyl isoquinoline compound of the intermediate-acting neuromuscular blockade (NMB) class, has high potency, causes a minor release of histamine, less laudanosine production, undergoes organ-independent Hofmann elimination, and has a slower onset time [1,2]. In adults, cisatracurium given at a dose of $0.15 \mathrm{mg} / \mathrm{kg}\left(3 \times \mathrm{ED}_{95}\right)$ has been found to have an onset time of $220 \mathrm{~s}$, which is much slower than succinylcholine or rocuronium [3]. However, several trials with ketamine, magnesium sulfate, ephedrine, and priming dose of cisatracurium, have reported to techniques reduce the onset time of cisatracurium and improve intubating conditions [4-8].

The onset time of cisatracurium was reduced by $40 \%$ when pre-treatment with ephedrine $70 \mu \mathrm{g} / \mathrm{kg}$ was administered [7]. A low-dose of ephedrine $(70 \mu \mathrm{g} / \mathrm{kg})$ plus a priming dose with cisatracurium before an intubating dose improved clinical intubating conditions by $36 \%$ at $60 \mathrm{~s}$ after the intubating dose of cisatracurium [6]. However, the hemodynamic response to laryngoscopy and endotracheal intubation was significantly increased during the induction [9]. Anesthesiologists should be aware of the potential adverse hemodynamic consequences of ephedrine pretreatment prior to tracheal intubation. Therefore, an optimal dose of ephedrine should be determined to minimize adverse hemodynamic responses during the induction of anesthesia. We chose a dose of ephedrine as 30,70 and $110 \mu \mathrm{g} / \mathrm{kg}$, to know the effects of small and large than previous reported dose $(70 \mu \mathrm{g} / \mathrm{kg})$ [6,7].

In this study, we compared the influence of saline and ephedrine 30,70 , or $110 \mu \mathrm{g} / \mathrm{kg}$ given before induction on (1) intubating conditions $1.5 \mathrm{~min}$ after cisatracurium $0.15 \mathrm{mg} / \mathrm{kg}$ and (2) hemodynamic changes (heart rate and systolic and diastolic blood pressure) during induction time.

\section{Materials and Methods}

Before this study was performed, approval (IRB File No.: 2012-06-026) was obtained from the Hospital Ethics Committee and written informed consent was obtained from all patients. Adult patients $(\mathrm{n}=140)$ aged 20 to 64 years with an American Society of Anesthesiologists physical status I or II who underwent elective surgery under general anesthesia with tracheal intubation in the supine position were enrolled in this study. Using a computer-generated program, 35 patients were allocated randomly to one of four study groups: pretreatment with ephedrine $30 \mu \mathrm{g} / \mathrm{kg}$ (Group 30), ephedrine $70 \mu \mathrm{g} / \mathrm{kg}$ (Group 70), ephedrine $110 \mu \mathrm{g} / \mathrm{kg}$ (Group 110), or $3 \mathrm{ml} \mathrm{NaCl} 0.9 \%$ (Group C) given $30 \mathrm{~s}$ before anesthesia induction (Fig. 1). Patients were excluded for the following reasons: those expected to have a difficult airway, neuromuscular, hepatic, or renal diseases, ischemic heart disease or a history of myocardial infarction within the last year, pregnancy and those with a body weight $20 \%$ greater than their ideal body weight.

No premedication was given. On arrival in the operating room, automatic monitoring with noninvasive arterial blood pressure, oxygen saturation and electrocardiography (ECG) was begun. Bispectral index (BIS) was monitored using a BIS XP monitor (Model A 2000, Aspect Medical Systems, Natick, MA, USA) and was measured every $10 \mathrm{~s}$ during anesthesia.

Anesthesia was induced with remifentanil $0.5 \mu \mathrm{g} / \mathrm{kg} / \mathrm{min}$ injected intravenously over $2 \mathrm{~min}$ followed by midazolam $3 \mathrm{mg}$ and propofol $1.5 \mathrm{mg} / \mathrm{kg}$ injected intravenously over $30 \mathrm{~s}$ by an anesthesiologist blinded to group assignment. As soon as the patient lost consciousness, ventilation via facemask with $50 \%$ oxygen-enriched air was manually administered to keep the end-tidal carbon dioxide tension within the range of 30 to 35 $\mathrm{mmHg}$ until tracheal intubation. Anesthesia was maintained with propofol $(3 \mathrm{mg} / \mathrm{kg} / \mathrm{h})$ and remifentanil $(0.1-0.3 \mu \mathrm{g} / \mathrm{kg} / \mathrm{min})$

Induction sequence

Group C: saline $(n=35)$

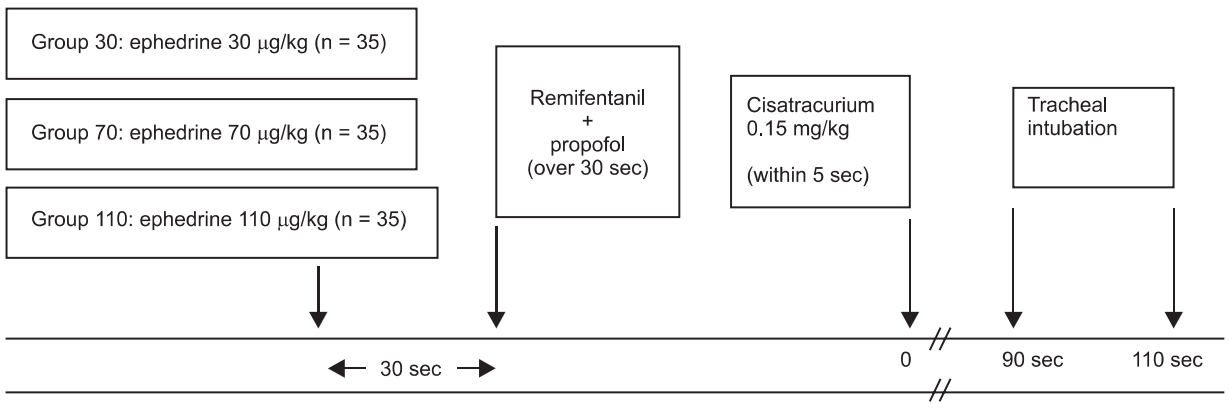

Time

Fig. 1. Time line of induction. 
with the goal of maintaining the BIS below 50 .

Neuromuscular function was assessed using acceleromyography of the adductor pollicis muscle (TOF-Watch SX ${ }^{\circledR}$, Organon Ltd., Dublin, Ireland). Two electrodes (Cleartrode ${ }^{\mathrm{TM}}$, Ref 1720003, ConMed ${ }^{\circledR}$, Utica, NY, USA) were placed over the ulnar nerve of the hands and an accelerometer was fixed to the volar aspect of the thumb. Neuromuscular monitoring began immediately when the patient lost consciousness. A 5-s 50-Hertz $(\mathrm{Hz})$ supramaximal tetanic stimulus was administered for calibration of acceleromyography [10]. Calibration was performed using the CAL2 mode of the TOF-Watch SX ${ }^{\circledR}$, which calibrates automatically by searching for the supramaximal level. Train-offour (TOF) stimulations $(0.2 \mathrm{~ms}$ in duration at $2 \mathrm{~Hz}$ with supramaximal current) were applied every $15 \mathrm{~s}$ during anesthesia. All neuromuscular data was collected on a laptop computer.

Cisatracurium $(0.15 \mathrm{mg} / \mathrm{kg})$ was administered rapidly within $5 \mathrm{~s}$ after stabilization of control responses. Tracheal intubation was performed $1.5 \mathrm{~min}$ after cisatracurium within $20 \mathrm{~s}$ by an anesthesiologist blinded to the protocol and with at least 3 years of experience. The same physician also assessed the intubating conditions. Intubating conditions were graded according to the criteria of Fuchs-Buder et al. [11]: easy of laryngoscopy $(0=$ difficult, 1 = fair, 2 = easy), position of vocal cords ( $0=$ closed, 1 = intermediate/moving, 2 = adducted), reaction to intubation (diaphragmatic movement/coughing) ( 0 = vigorous/sustained, 1 = slight, 2 =none). A score of 5 or 6 was considered excellent, 3 or 4 good, and 0 to 2 poor. The point of disappearance of the first twitch of TOF stimulation was recorded as the onset time of cisatracurium at the adductor pollicis. A diagram of the induction is shown in Fig. 1. Skin temperature on the hand was kept above $32^{\circ} \mathrm{C}$ by wrapping the arm in cotton wool and core temperature was kept above $35^{\circ} \mathrm{C}$ with a corrugated heating circuit and air warming.

Systolic and diastolic blood pressure, heart rate and BIS were measured and recorded at the following times: preinduction, immediately prior to intubation, and $1 \mathrm{~min}$ and $3 \mathrm{~min}$ after intubation. A $20 \%$ change in hemodynamic variables from baseline values was regarded as an adverse effect. The presence of ar- rhythmias on the ECG monitor was recorded. All patients were interviewed by a blinded investigator $24 \mathrm{~h}$ after surgery and assessed for awareness during anesthetic induction.

Statistical analyses were performed using SPSS statistical software (Windows ver. 19.0, SPSS Inc, Chicago, IL, USA). In this study, sample size calculations were taken from a previous study [7]. On the basis of a relevant $20 \%$ change (SD 24\% change) in the onset time (167 $\pm 64.8 \mathrm{~s}$ ) of cisatracurium, we calculated that 32 patients would be needed to test the null hypothesis at a significance of 0.05 and a power of 0.80 . We enrolled 35 patients to account for a $10 \%$ dropout rate. One-way analysis of variance (ANOVA) was performed for continuous variables (i.e., age, weight, height, anesthetic time and BIS). To study the effects of time and group allocation on each of the variables, repeatedmeasure ANOVA was used to compare the hemodynamic parameters between preinduction values and time (three levels). When the results were significant, the Student-Newman-Keuls post-test was used to localize significant differences. One-way ANOVA was used between groups for onset time and multiple comparisons were made with the Dunn's method if a significant difference was found. The Kruskal-Wallis ANOVA with Tukey's test for post hoc analysis was used to determine the significance of differences with respect to the intubation conditions. The data were expressed as the mean \pm SD (number, \%). P values $<0.05$ were considered statistically significant.

\section{Results}

Among the 140 patients recruited for this study, none were excluded. No significant differences in age, gender, weight, height, anesthetic time or BIS were observed between groups (Table 1). The onset time of cisatracurium $0.15 \mathrm{mg} / \mathrm{kg}$ was shorter after pre-treatment with ephedrine (Group 30: $155.4 \pm 44.7 \mathrm{~s}$, Group 70: $152.6 \pm 40.3$ s, Group 110: $151.2 \pm 51.6$ s) compared to placebo (Group C: $224.6 \pm 56.9$ s) $(\mathrm{P}<0.001)$ (Fig. 2). Overall excellent and good intubating conditions were significantly increased after larger ephedrine doses (Group 70 and Group 110; 25.7 and 60, 22.9 and $60 \%$, respectively) than placebo ( 0 and

Table 1. Demographic Data

\begin{tabular}{|c|c|c|c|c|c|}
\hline & Group C & Group 30 & Group 70 & Group 110 & $\mathrm{P}$ \\
\hline $\mathrm{n}$ & 35 & 35 & 35 & 35 & \\
\hline Age (yr) & $40.0 \pm 10.1(20-54)$ & $42.8 \pm 12.7(21-64)$ & $40.2 \pm 12.0(20-58)$ & $42.7 \pm 9.8(20-60)$ & 0.727 \\
\hline $\mathrm{M} / \mathrm{F}$ & $14 / 21$ & $16 / 19$ & $18 / 17$ & $18 / 17$ & 0.741 \\
\hline Weight $(\mathrm{kg})$ & $64.0 \pm 10.6$ & $60.9 \pm 10.7$ & $61.6 \pm 10.2$ & $65.3 \pm 11.6$ & 0.288 \\
\hline Height $(\mathrm{cm})$ & $165.2 \pm 10.0$ & $162.5 \pm 10.3$ & $165.0 \pm 8.7$ & $166.9 \pm 9.1$ & 0.288 \\
\hline Anesthetic time (min) & $126.7 \pm 67.2$ & $153.4 \pm 112.0$ & $124.9 \pm 63.6$ & $143.1 \pm 111.9$ & 0.51 \\
\hline BIS & $33.4 \pm 12.1(17-60)$ & $31.0 \pm 8.7(19-55)$ & $32.0 \pm 11.4(12-59)$ & $34.3 \pm 11.9(21-59)$ & 0.614 \\
\hline
\end{tabular}

Values are presented as mean \pm SD (range) or numbers of patients. BIS: bispectral index just after intubation, Group C: saline, Group 30: ephedrine 30 $\mu \mathrm{g} / \mathrm{kg}$, Group 70: ephedrine $70 \mu \mathrm{g} / \mathrm{kg}$, Group 110: ephedrine $110 \mu \mathrm{g} / \mathrm{kg}$. 


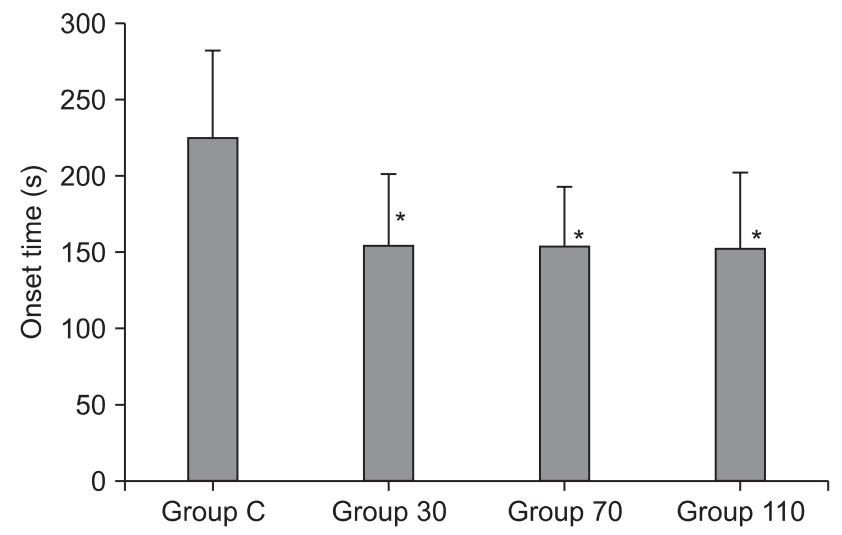

Fig. 2. Onset time of block after cisatracurium $0.15 \mathrm{mg} / \mathrm{kg}$ in each group $(\mathrm{n}=35)$. Values are mean $\pm \mathrm{SD}$. Group $\mathrm{C}=$ saline; Group 30 $=$ ephedrine $30 \mu \mathrm{g} / \mathrm{kg}$; Group $70=$ ephedrine $70 \mu \mathrm{g} / \mathrm{kg}$; Group $110=$ ephedrine $110 \mu \mathrm{g} / \mathrm{kg}$. ${ }^{*} \mathrm{P}<0.001$ versus Group C.

Table 2. Intubating Conditions

\begin{tabular}{lllrl}
\hline & \multicolumn{3}{c}{ Intubating conditions } & \multirow{2}{*}{ P } \\
\cline { 2 - 4 } & Excellent & \multicolumn{1}{c}{ Good } & \multicolumn{1}{c}{ Poor } & \\
\hline Group C $(\mathrm{n}=35)$ & $0(0 \%)$ & $22(62.9 \%)$ & $13(37.1 \%)$ & \\
Group 30 $(\mathrm{n}=35)$ & $3(8.6 \%)$ & $27(77.1 \%)$ & $5(14.3 \%)$ & NS \\
Group 70 $(\mathrm{n}=35)$ & $9(25.7 \%)$ & $21(60.0 \%)$ & $5(14.3 \%)$ & $<0.05$ \\
Group 110 $(\mathrm{n}=35)$ & $8(22.9 \%)$ & $21(60.0 \%)$ & $6(17.1 \%)$ & $<0.05$ \\
\hline
\end{tabular}

Values are presented as numbers of patients (\%). Intubating condition scales are followed Fuchs-Buder et al. (Reference 11). Group C: saline, Group 30: ephedrine $30 \mu \mathrm{g} / \mathrm{kg}$, Group 70: ephedrine $70 \mu \mathrm{g} / \mathrm{kg}$, Group 110: ephedrine $110 \mu \mathrm{g} / \mathrm{kg}$, NS: no significant. P values are compared to Group C.

62.9\%) $(\mathrm{P}<0.05)$, but there were no differences between doses of ephedrine (Table 2). Systolic and diastolic blood pressure and heart rate at $1 \mathrm{~min}$ after tracheal intubation were significantly increased than preinduction and before intubation in all groups $(\mathrm{P}<0.001)$ (Figs. 3 and 4$)$, but there were no differences among the groups. Endotracheal intubation caused significant increases in systolic and diastolic blood pressure (systolic/diastolic blood pressure: $>200 / 100 \mathrm{mmHg}$ ) at $1 \mathrm{~min}$ in 5 patients (14\%) of Group 110 with no patients in other groups (Fig. 3). No arrhythmias occurred during the study period.

\section{Discussion}

The main finding of this study was that pre-treatment with ephedrine 70 and $110 \mu \mathrm{g} / \mathrm{kg}$ reduced the onset time (70 s) of cisatracurium and improved intubating conditions $1.5 \mathrm{~min}$ after cisatracurium. However, ephedrine $110 \mu \mathrm{g} / \mathrm{kg}$ was associated with marked hypertension (systolic/diastolic blood pressure: $>200 / 100 \mathrm{mmHg}$ ) after tracheal intubation.

In the previous study, cisatracurium had a decreased onset

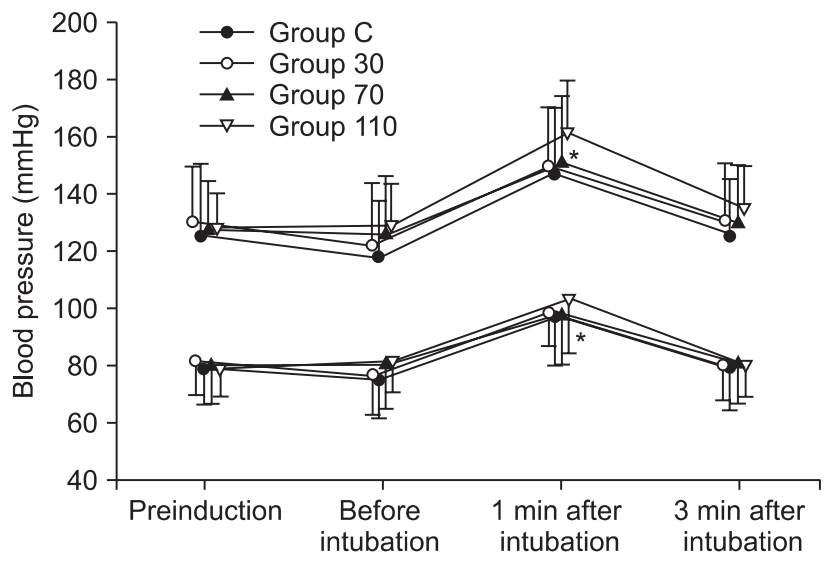

Fig. 3. Changes in systolic and diastolic blood pressure in each group $(\mathrm{n}=35)$ during induction. Values are mean $\pm \mathrm{SD}$. Group $\mathrm{C}=$ saline; Group 30 = ephedrine $30 \mu \mathrm{g} / \mathrm{kg}$; Group 70 = ephedrine $70 \mu \mathrm{g} / \mathrm{kg}$; Group $110=$ ephedrine $110 \mu \mathrm{g} / \mathrm{kg}$. $* \mathrm{P}<0.001$ versus preinduction and before intubation levels.

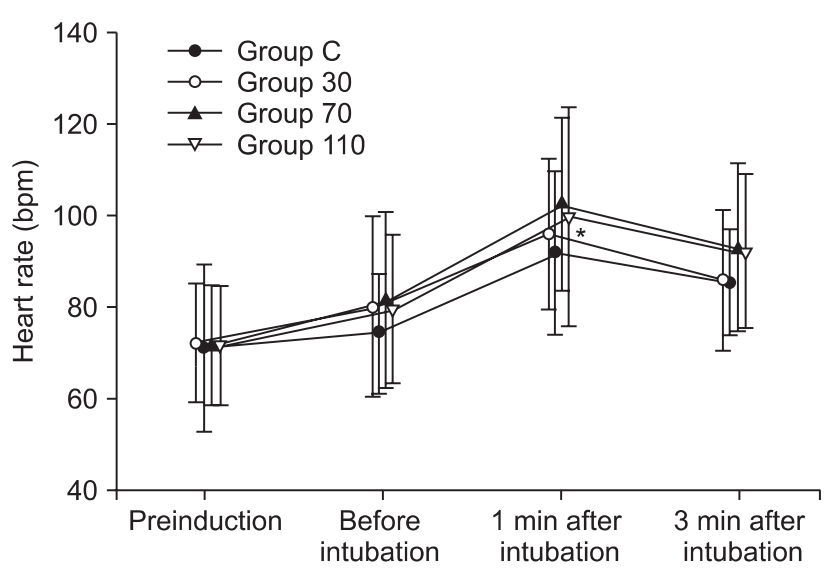

Fig. 4. Changes in heart rate in each group $(n=35)$ during induction. Values are mean $\pm \mathrm{SD}$. Group C = saline; Group $30=$ ephedrine $30 \mu \mathrm{g} /$ $\mathrm{kg}$; Group 70 = ephedrine $70 \mu \mathrm{g} / \mathrm{kg}$; Group $110=$ ephedrine $110 \mu \mathrm{g} / \mathrm{kg}$. $* \mathrm{P}<0.001$ versus preinduction and before intubation levels.

time with increased doses $(0.2 \mathrm{mg} / \mathrm{kg})$ up to $35 \%$ [3]. Although this increasing dose could reduce the onset time of cisatracurium, adverse effects may occur, such as the development of muscle weakness or increased action duration of neuromuscular blockade [3]. The priming technique is an alternative to shorten the onset time of NMB. However, fractional cisatracurium doses have not been shown to shorten the NMB onset time as compared to bolus injections $[8,12]$. The combination of low-dose ephedrine $(70 \mu \mathrm{g} / \mathrm{kg})$ and a low priming dose $(0.005 \mathrm{mg} / \mathrm{kg})$ of cisatracurium improved clinical intubating conditions at $60 \mathrm{~s}$ after the intubating dose of cisatracurium compared to priming without ephedrine or ephedrine without priming [6]. However, awake patients may suffer from serious adverse events such as blurred vision, diplopia, heavy eyelids, muscle weakness, dif- 
ficulty swallowing, and voice disorders during the relatively long priming interval [13]. Additionally, this previous study did not simultaneously evaluate the degree of $\mathrm{NMB}$ after atracurium administration. In our study, an onset time of $70 \mathrm{~s}$ was obtained after pre-treatment with ephedrine compared to the placebo after $0.15 \mathrm{mg} / \mathrm{kg}$ of cisatracurium. Although onset time at the larynx was different than that at the adductor pollicis [14], we suspect that pre-treatment with ephedrine may also reduce the onset time at the larynx after cisatracurium, which may be a contributing factor to improve intubating conditions.

Occasionally, the hemodynamic responses to propofol during the induction sequence were obtunded by pre-treatment with ephedrine [15]. However, in most patients, tachycardia and hypertension were exacerbated by tracheal intubation when the pretreatment of ephedrine was added. The use of the ephedrine/ propofol mixtures for elderly patients was not recommended due to the risk of tachycardia-inducing myocardial ischemia [16]. In our study, evidence of the association between ephedrine and marked hypertension was seen $1 \mathrm{~min}$ after intubation in 5 patients after pretreatment with ephedrine $110 \mu \mathrm{g} / \mathrm{kg}$. Pretreatment with ephedrine $30 \mu \mathrm{g} / \mathrm{kg}$ had stable hemodynamic values but no improvement in intubating conditions. However, ephed- rine $70 \mu \mathrm{g} / \mathrm{kg}$ was the optimal dose and was found to minimize adverse effects, reduce onset time of cisatracurium and improve intubating conditions.

The rapidity of the onset of $\mathrm{NMB}$ at the adductor pollicis muscle was clearly related to cardiac output (CO) [17]. This study is limited in that we made no measurements of cardiac output and thus we cannot confirm the time to peak effect of ephedrine as related to blood flow. In our previous study, CO and systemic vascular resistance after preinjection of ephedrine were greater until 1 min after tracheal intubation compared with placebo [18]. We suspect that increased cardiac output due to ephedrine administration may contribute to the rapid onset of cisatracurium.

Although severe adverse effects after the pretreatment with ephedrine were not found in relatively healthy patients from this study, we should consider that a larger dose of ephedrine is not indicated in patients with myocardial ischemia and hypertension due to the possibility of serious adverse effects.

In conclusion, pretreatment with ephedrine $70 \mu \mathrm{g} / \mathrm{kg}$ improved intubating conditions $1.5 \mathrm{~min}$ after cisatracurium administration and facilitated the onset of cisatracurium (70 s) without adverse hemodynamic effects.

\section{References}

1. Lien CA, Belmont MR, Abalos A, Eppich L, Quessy S, Abou-Donia MM, et al. The cardiovascular effects and histamine-releasing properties of 51W89 in patients receiving nitrous oxide/opioid/barbiturate anesthesia. Anesthesiology 1995; 82: 1131-8.

2. Doenicke A, Soukup J, Hoernecke R, Moss J. The lack of histamine release with cisatracurium: a double-blind comparison with vecuronium. Anesth Analg 1997; 84: 623-8.

3. Lighthall GK, Jamieson MA, Katolik J, Brock-Utne JG. A comparison of the onset and clinical duration of high doses of cisatracurium and rocuronium. J Clin Anesth 1999; 11: 220-5.

4. Ahn BR, Kim SH, Yu BS, Lim KJ, Sun JJ. The effect of low dose ketamine and priming of cisatracurium on the intubating condition and onset time of cisatracurium. Korean J Anesthesiol 2012; 63: 308-13.

5. Kim SH, So KY, Jung KT. Effect of magnesium sulfate pretreatment on onset and recovery characteristics of cisatracurium. Korean J Anesthesiol 2012; 62: 518-23.

6. Leykin Y, Dalsasso M, Setti T, Pellis T. The effects of low-dose ephedrine on intubating conditions following low-dose priming with cisatracurium. J Clin Anesth 2010; 22: 425-31.

7. Albert F, Hans P, Bitar Y, Brichant JF, Dewandre PY, Lamy M. Effects of ephedrine on the onset time of neuromuscular block and intubating conditions after cisatracurium: preliminary results. Acta Anaesthesiol Belg 2000; 51: 167-71.

8. Deepika K, Kenaan CA, Bikhazi GB, Martineau DB. Influence of the priming technique on pharmacodynamics and intubating conditions of cisatracurium. J Clin Anesth 1999; 11: 572-5.

9. Horak J, Weiss S. Emergent management of the airway. New pharmacology and the control of comorbidities in cardiac disease, ischemia, and valvular heart disease. Crit Care Clin 2000; 16: 411-27.

10. Kopman AF, Kumar S, Klewicka MM, Neuman GG. The staircase phenomenon: implications for monitoring of neuromuscular transmission. Anesthesiology 2001; 95: 403-7.

11. Fuchs-Buder T, Claudius C, Skovgaard LT, Eriksson LI, Mirakhur RK, Viby-Mogensen J. Good clinical research practice in pharmacodynamic studies of neuromuscular blocking agents II: the Stockholm revision. Acta Anaesthesiol Scand 2007; 51: 789-808.

12. Braga Ade F, Potério GM, Braga FS, Cremonesi E, Siqueira FP, Carvalho VH. Priming versus bolus: a comparative study with different cisatracurium doses. Rev Bras Anestesiol 2003; 53: 9-16.

13. Mirakhur RK, Lavery GG, Gibson FM, Clarke RS. Intubating conditions after vecuronium and atracurium given in divided doses (the priming technique). Acta Anaesthesiol Scand 1986; 30: 347-50. 
14. Kim KS, Chung CW, Shin WJ. Cisatracurium neuromuscular block at the adductor pollicis and the laryngeal adductor muscles in humans. Br J Anaesth 1999; 83: 483-4.

15. Gamlin F, Vucevic M, Winslow L, Berridge J. The haemodynamic effects of propofol in combination with ephedrine. Anaesthesia 1996; 51: 488-91.

16. Gamlin F, Freeman J, Winslow L, Berridge J, Vucevic M. The haemodynamic effects of propofol in combination with ephedrine in elderly patients (ASA groups 3 and 4). Anaesth Intensive Care 1999; 27: 477-80.

17. Iwasaki H, Igarashi M, Yamauchi M, Namiki A. The effect of cardiac output on the onset of neuromuscular block by vecuronium. Anaesthesia 1995; 50: 361-2.

18. Kim KS, Cheong MA, Jeon JW, Lee JH, Shim JC. The dose effect of ephedrine on the onset time of vecuronium. Anesth Analg 2003; 96 : $1042-6$. 